\title{
Association between Erectile Dysfunction and Obesity
}

\section{Heitor Zancheta de Andrade1, Gilberto Borges de Brito², Moacir Fernandes de Godoy ${ }^{3}$, Thiago da Silveira Antoniassi ${ }^{4}$, Luis Cesar Fava Spessoto ${ }^{4}$, Fernando Nestor Facio Junior ${ }^{4}$}

\author{
${ }^{1}$ Undergraduate student School of Medicine São Jose Rio Preto - FAMERP \\ ${ }^{2}$ Professor of the Surgery Department - Hospital de Base/FAMERP \\ ${ }^{3}$ Professor of the Cardiology and Cardiovascular Surgery Department - Hospital de Base/FAMERP \\ ${ }^{4}$ Professor of the Surgical Specialties Department - Hospital de Base/FAMERP \\ Medical School in São José do Rio Preto, São José do Rio Preto, SP
}

\begin{abstract}
There are several risk factors associated with erectile dysfunction (ED) and so it is important to identify them to improve the therapeutic approach. The objective of this study was to evaluate the association between obesity and ED. In this prospective cross-sectional observational study, the IIEF questionnaire was used to evaluate erectile function. The total sample of 38 subjects was divided into two groups; 23 obese individuals (BMI $\geq 30)$ with a mean BMI of 46.07, and 15 non-obese subjects (BMI <30) with a mean BMI of 25.9. Some degree of ED was evidenced in $52.17 \%$ of the obese and in $6.6 \%$ of the non-obese subjects. Statistical significance was found between the two groups using logistic regression. Thus, obesity is a risk factor for ED.
\end{abstract}

Keywords: Erectile Dysfunction, Risk Factors, Obesity

\section{Introduction}

Over the last decades obesity has become a world public health problem. Studies show that around 2 billion people around the world are overweight or obese. ${ }^{1}$ In addition, there was a $28.3 \%$ increase in deaths related to increases in body mass. ${ }^{2}$ According to the Brazilian Ministry of Health, $18.9 \%$ of Brazilians are obese $\left(B M I \geq 30 \mathrm{~kg} / \mathrm{m}^{2}\right)$ and another $53.8 \%$ are overweight with these rates tending to rise. $^{3}$

Type 2 diabetes, cardiovascular disease and systemic arterial hypertension are among the most important conditions found in obese individuals. ${ }^{4}$ In addition, obesity has a significant impact on the quality of the sexual life with decreased desire and performance, often leading to the partner avoiding sexual intercourse. ${ }^{5}$

Erectile dysfunction (ED) is also associated with androgenic disorders such as altered testosterone levels; In morbid obesity, testosterone is often reduced and consequently there is loss of quality of erection. ${ }^{6}$
It has been shown that surgery to correct morbid obesity improves overall quality of life, especially in respect to physical conditions. ${ }^{7}$ According to Araújo et al., ${ }^{8}$ who studied patients submitted to bariatric surgery, improvements, including better erectile function, sexual desire and orgasm, occurred in more than half of the cases they studied.

The objective of this research was to study whether there is an association between obesity and ED.

\section{Methods \\ Male patients with $\left(\mathrm{BMI} \geq 30 \mathrm{~kg} / \mathrm{m}^{2}\right)$ and without obesity (BMI $<30 \mathrm{~kg} / \mathrm{m}^{2}$ ) were enrolled in a prospective cross-sectional observational study. The subjects were attended at a university hospital from January to July 2017. This study was approved by the Research Ethics Committee of the Medical School in São José do Rio Preto (FAMERP), state of São Paulo, Brazil.}

To determine the presence of ED in the enrolled patients, the International Erectile Function Index-5 (IIFE-5) was used to stratify patients with or without ED. ${ }^{9}$

This article is published under the terms of the Creative Commons Attribution License 4.0 Author(s) retain the copyright of this article. Publication rights with Alkhaer Publications.

Published at: http://www.ijsciences.com/pub/issue/2017-10/

DOI: 10.18483/ijSci.1451; Online ISSN: 2305-3925; Print ISSN: 2410-4477 
Data were collected from the patients using a standardized self-responding IIFE-5 questionnaire. The questionnaires after completion were randomly placed in an envelope by the patient in order to avoid embarrassment. Descriptive statistics (mean, standard deviation, median, minimum and maximum) were used for data analysis.

\section{Results}

Of the 38 subjects studied, $23(60.5 \%)$ were obese and $15(39.5 \%)$ were not obese. The mean BMI of the obese group was $46.1 \pm 13.2 \mathrm{~kg} / \mathrm{m}^{2}$ (range: $30.2-79$ $\mathrm{kg} / \mathrm{m}^{2}$, the age ranged from 26 to 59 years (mean: $40.9 \pm 9.3$ years) and the mean IIFE score was 19.4. ED was identified in $52.17 \%(\mathrm{n}=12)$ of obese individuals by analyzing the individual data of the IIFE scores (Figure 1).

In the non-obese group, the mean BMI was $25.9 \pm 5.2$ $\mathrm{kg} / \mathrm{m}^{2}$ (range: $21.3-28.7 \mathrm{~kg} / \mathrm{m}^{2}$ ), the age ranged from 23 to 59 years (mean: $31.6 \pm 22.6$ years) and the mean IIEF score was 23.6. On analyzing the individual data of IIFE scores, only $6.6 \%(n=1)$ of non-obese individuals were identified with ED (Table 1).

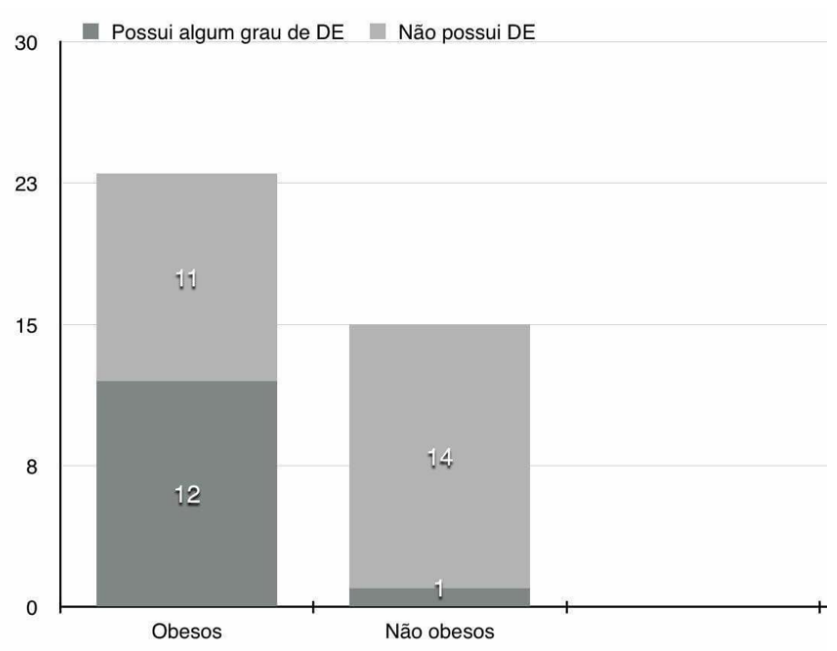

Figure 1 - Distribution of obese and non-obese individuals with erectile dysfunction.

Table 1 - IIEF data obtained from the studied groups.

\begin{tabular}{lccc}
\hline IIEF & Obese & Not obese & Total \\
\hline IIEF $\geq 30 \mathrm{~kg} / \mathrm{m}^{2}$ & 11 & 14 & 25 \\
IIEF $<30 \mathrm{~kg} / \mathrm{m}^{2}$ & 12 & 1 & 16 \\
\hline Total & 23 & 15 & 38 \\
\hline
\end{tabular}

The data on obesity and age were compared in relation to the presence of ED using the logistic regression method. This showed that obesity is an independent risk factor for ED ( $\mathrm{p}$-value $<0.05$ ), while age is no longer a predictor in this comparison ( $\mathrm{p}$ value $>0.05$ )

\section{Discussion}

The incidence of obesity is increasing in Brazil, ${ }^{10}$ and it is associated with several other comorbidities; obesity is an isolated risk factor for cardiovascular diseases. ${ }^{11}$ Studies have shown that obesity is clearly a predictive factor for DE. ${ }^{12,13}$ The Massachusetts Male Aging study found evidence of an increase in the overall prevalence of ED from $17 \%$ to $45 \%$ in individuals with $\mathrm{BMI} \geq 30 \mathrm{~kg} / \mathrm{m}^{2} .{ }^{14}$ In another study, health professionals found that patients with a BMI $>28.7 \mathrm{~kg} / \mathrm{m}^{2}$ had a $30 \%$ higher risk of ED compared to those with a BMI $<23.2 \mathrm{~kg} / \mathrm{m}^{2}$. ${ }^{15}$

However, there is still disagreement in the literature on whether obesity behaves as an isolated risk factor for ED. A study coordinated by Feldman et al. ${ }^{16}$ did not demonstrate any correlation between obesity and ED in the general population, but these authors stated that obesity correlates with other comorbidities such as hypertension, dyslipidemia, thyroid disease and diabetes mellitus, which have direct correlations with ED. Similar conclusions were reported by Chung et al. ${ }^{17}$ who assessed the erectile capacity of 321 men with ED by means of Doppler ultrasonography of the cavernous arteries and concluded that there were no significant differences in erectile function between obese and non-obese patients when cardiovascular risk factors are removed.

On the other hand, a study carried out by Esposito et al. ${ }^{18}$ found an improvement in severe ED in a patient with morbid obesity without associated comorbidities after weight loss and lifestyle changes over a period of two years.

The present study found a strong association between ED and obesity, which corroborates data reported in the literature, but it was not able to assess whether ED is due to obesity or associated comorbidities, such as hypertension, diabetes mellitus, dyslipidemias, social stigma and the self-esteem of the patient. Most of the obese patients had at least one other associated comorbidity with hypertension being the most common $(60.8 \%)$.

In addition, it is important to mention that with regard to the reliability of the responses to the questionnaire, it is possible that some respondents tend to give more positive answers about their sexuality than what is really the case despite the appropriate measures being taken. However, numerous studies conducted 
addressing the reliability of the sexual function questionnaire (IIEF) demonstrate that it is valid and well understood, and its high sensitivity and specificity makes it an effective and adequate instrument to evaluate erectile function.

Further evidence that reinforces the relationship between obesity and ED is the improvement in erectile function and quality of life of patients who perform some type of treatment for obesity, whether it be lifestyle changes ${ }^{18}$ or a surgical approach. A meta-analysis performed by Glina et al. ${ }^{19}$ on changes in the quality of sexual life of patients submitted to bariatric surgery, regardless of the technique, showed a substantial improvement in the erectile and sexual function of these patients after the surgical procedure.

\section{Conclusion}

With the data presented, we conclude that obesity is a predictor of ED, but more studies are still needed to determine whether obesity acts alone as the cause of ED or whether it is caused by obesity-associated comorbidities.

\section{References}

1. Friedrich M. Global obesity epidemic worsening. JAMA 2017;318(7):603.

2. Gregg EW, Shaw JE. Global health effects of overweight and obesity. N Engl J Med 2017;377(1):80-81.

3. Ministério da Saúde. Em dez anos, obesidade cresce $60 \%$ no Brasil e colabora para maior prevalência de hipertensão e diabetes. 2017; http://portalsaude.saude.gov.br/index.php/cidadao/principal/a gencia-saude $/ 28108$.

4. Franz MJ. Managing obesity in patients with comorbidities. J Am Diet Assoc 1998;98(10 Suppl 2):S39-43.

5. Kolotkin RL, Binks M, Crosby RD, Ostbye T, Gress RE, Adams TD. Obesity and sexual quality of life. Obesity 2006;14:472-9.

6. Allan CA, McLachlan RI. Androgens and obesity. Curr Opin Endocrinol Diabetes Obes 2010;17(3):224-32.

7. Barreto Villela N, Braghrolli Neto O, Lima Curvello K, Eduarda Paneili B, Seal C, Santos D, et al. Quality of life of obese patients submitted to bariatric surgery. Nutr Hosp 2004;19(6):367-71.

8. Araújo AA, Brito AM, Ferreira Mde N, Petribú K, Mariano MH. Changes the sexual quality of life of the obese submitted Fobi-Capella gastroplasty surgery. Rev Col Bras Cir 2009;36(1):42-8.

9. Ribeiro PJL, Santos A. Metric properties of a Portuguese version of the abridged, 5 -item version of the international index of erectile function (IIEF-5). Psic, Saude \& Doencas 2007;8(2):271-4.

10. 10. Frankenfield DC, Rowe WA, Cooney RN, Smith JS, Becker D. Limits of body mass index to detect obesity and predict body com- position. Nutrition 2001;17(1):26-30

11. Tan RS, Pu JS. Impact of obesity on hypogonadism in the andropause. Int J Androl 2002;25:195-201.

12. Walczack MK, Lokhandwala N. Prevalent of cardiovascular risk factors in erectile dysfunction. J Ged Specif Med 2002;5(6): 19-24.

13. Derby CA, Mohr BA, Goldstein I, Feldman HA, Johannes CB, Mckinlay JB. Modifiable risk factors and erectile dysfunction: can lifestyle changes modify risk? Urology 2000;56:302-6.
14. Feldman HA, Johannes CB, Derby CA, Kleinman KP, Mohr $\mathrm{BA}$, Araujo AB, et al. Erectile dysfunction and coronary risk factors: prospective results from the Massachusetts male aging study. Prev Med 2000;30(4):328-38.

15. Diaz-Arjonilla M, Schwarcz M, Swerdloff RS, Wang C. Obesity, low testosterone levels and erectile dysfunction. Int J Impot Res 2009;21(2):89-9

16. Feldman HA, Goldstein I, Hatzchristou DG, Krane RJ, McKinlay JB. Impotence and its medical and psychological correlates: results of the Massachusetts Male Ageing Study. J Urol. 1994;151(1):54-61.

17. Chung WS, Sohn JH, Park YY. Is obesity an underlying factor in erectile dysfunction? Eur Urol. 1999;36(1):68-70.

18. Esposito K, Giugliano F, Di Palo O, Giugliano G, Marfella $\mathrm{R}$, D'Andrea F, et al. Effect of lifestyle changes on erectile dysfunction in obese men: a randomized controlled trial. JAMA 2004; 291(24):2978-84.

19. Glina FPI, de Freitas Barboza JW, Nunes VM, et al. What is the impact of bariatric surgery on erectile function? A systematic review and meta-analysis. Sex Med Rev 2017;5:393-402. 